\title{
Self-propelling surfactant droplets in chemically-confined microfluidics - cargo transport, drop-splitting and trajectory control
}

Citation for published version (APA):

Sinz, D. K. N., \& Darhuber, A. A. (2012). Self-propelling surfactant droplets in chemically-confined microfluidics cargo transport, drop-splitting and trajectory control. Lab on a Chip, 12(4), 705-707.

https://doi.org/10.1039/c2lc21082g

DOI:

10.1039/c2lc21082g

Document status and date:

Published: 01/01/2012

Document Version:

Publisher's PDF, also known as Version of Record (includes final page, issue and volume numbers)

Please check the document version of this publication:

- A submitted manuscript is the version of the article upon submission and before peer-review. There can be important differences between the submitted version and the official published version of record. People interested in the research are advised to contact the author for the final version of the publication, or visit the $\mathrm{DOI}$ to the publisher's website.

- The final author version and the galley proof are versions of the publication after peer review.

- The final published version features the final layout of the paper including the volume, issue and page numbers.

Link to publication

\footnotetext{
General rights

- You may freely distribute the URL identifying the publication in the public portal. follow below link for the End User Agreement:

www.tue.nl/taverne

Take down policy

If you believe that this document breaches copyright please contact us at:

openaccess@tue.nl

providing details and we will investigate your claim.
}

Copyright and moral rights for the publications made accessible in the public portal are retained by the authors and/or other copyright owners and it is a condition of accessing publications that users recognise and abide by the legal requirements associated with these rights.

- Users may download and print one copy of any publication from the public portal for the purpose of private study or research.

- You may not further distribute the material or use it for any profit-making activity or commercial gain

If the publication is distributed under the terms of Article 25fa of the Dutch Copyright Act, indicated by the "Taverne" license above, please 


\title{
Self-propelling surfactant droplets in chemically-confined microfluidics - cargo transport, drop-splitting and trajectory control $\dagger$
}

\author{
David K. N. Sinz and Anton A. Darhuber* \\ Received 8th November 2011, Accepted 19th December 2011 \\ DOI: $10.1039 / \mathrm{c} 2 \mathrm{lc21082 \textrm {g }}$
}

We demonstrate the applicability of self-propulsion as a passive driving mechanism for droplets in chemically-confined microfluidics. The droplets can be used to transport considerably sized solid cargo particles. We implemented thermal actuation as a steering mechanism for the droplets at fluidic junctions.

Open-surface microfluidic devices offer advantages over conventional pressure-driven channel-based microfluidic systems, such as easy access, but also suffer from draw-backs, e.g. the incompatibility with operation by mechanical pumps. ${ }^{1}$ Established liquid actuation techniques in open-surface microfluidics are optowetting, ${ }^{2}$ dielectrophoresis, ${ }^{3}$ thermocapillary actuation, ${ }^{4-6}$ and vibration ${ }^{7}$ as well as electrowetting, ${ }^{8-11}$ which has recently also been applied in open/ closed-surface hybrid devices. ${ }^{12}$ Specifically with respect to cheap, single-use-type devices, a drawback of these techniques is the necessity of an external power source and the integration of electrodes or electric heating elements into the microfluidic system. A viable alternative for these kind of devices are passive liquid actuation mechanisms, which have been demonstrated for closed ${ }^{13-16}$ as well as open-surface microfluidic devices. ${ }^{1}$

We illustrate the applicability of surfactant self-propulsion as a passive driving mechanism for droplets in chemically-confined microfluidics, eliminating the necessity of an externally powered actuation mechanism. The droplets, consisting of an insoluble surfactant, exhibit directed motion on thin films of a second liquid, termed sub-phase. These sub-phase layers are spatially confined by chemical surface patterns, forming fluidic pathways for the selfpropelling droplets. We demonstrate transport of solid cargo particles with these droplets as well as drop splitting and routing at fluidic junctions in the chemical patterning. The driving force for the droplet motion has its origin in the Marangoni-flows induced by the nonuniform surfactant distribution around the droplets which can even sustain droplet motion against gravity. ${ }^{17}$ Related propulsion

Mesoscopic Transport Phenomena Group, Department of Applied Physics, Eindhoven University of Technology, Postbus 513, 5600, MB, Eindhoven, The Netherlands

$\uparrow$ Electronic supplementary information (ESI) available: Appendix 1: description of chemicals, patterning procedure and commentary to video files. Video files: appendix 2: drop propulsion, appendix 3: droplet splitting, appendix 4: droplet steering, appendix 5: droplet steering with cargo, appendix 6: droplet steering via infrared laser. See DOI: $10.1039 / \mathrm{c} 2 \mathrm{lc} 21082 \mathrm{~g}$ mechanisms for drop transport along liquid-air ${ }^{18}$ as well as liquidsolid interfaces ${ }^{19}$ have been studied in recent years.

Our chemical patterning procedure, $\uparrow$ based on photolithography and self-assembling mono-layers of $1 \mathrm{H}, 1 \mathrm{H}, 2 \mathrm{H}, 2 \mathrm{H}$-perfluorooctyltrichlorosilane was previously described, ${ }^{20}$ along with the subsequent cleaning step. Using this procedure we created chemically patterned surfaces on Si-substrates and borosilicate glass slides (thickness $150 \mu \mathrm{m}$ ), with hydrophilic stripes of length $L \geq 220 \mathrm{~mm}$ and width $w=1.5 \mathrm{~mm}$ on a hydrophobic background, as sketched in Fig. 1(a).

For experiments without cargo, a droplet of the surfactant cis-9octadecen-1-ol (oleyl alcohol) is deposited near one end of the hydrophilic stripe using a glass fiber as a dip-pen. The droplet volumes $V_{D}$ in our experiments ranged from 4-60 nl. After droplet deposition, the sub-phase liquid (film thickness $h_{0}$ ), a $0.55 \mathrm{wt} \%$ solution of sodium dodecyl sulfate (SDS) in anhydrous glycerol, is evenly distributed on the remaining hydrophilic region using a Hamilton 1710RN gastight micro-syringe, excluding a small area around the surfactant droplet, see ESI. $\dagger$

Following deposition, the contact line of the sub-phase liquid advances towards the surfactant droplet due to capillary spreading, as illustrated in Fig. 1(b). When the advancing sub-phase rivulet comes

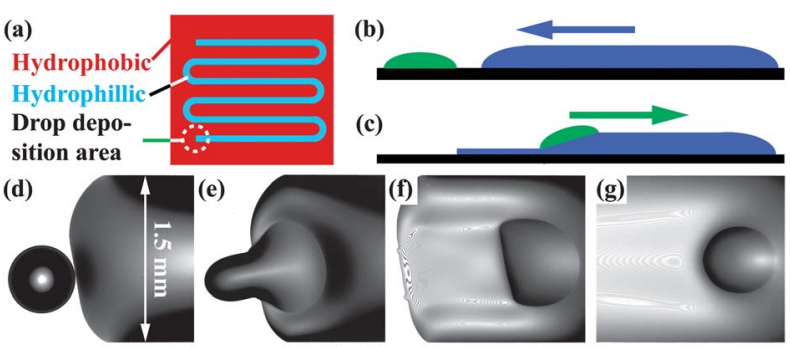

Fig. 1 (a) Sketch of a typical hydrophobic/hydrophilic surface pattern. $(b+c)$ Illustration of the mobilization of a droplet, (b) the sub-phase liquid spreads towards the droplets due to capillary pressure, (c) the droplet is in contact with the sub-phase, is mobilized, and propels along the confined sub-phase film. (d-g) Different stages in a propulsion experiment with initial film thickness $h_{0}=295 \mu \mathrm{m}$. (d) Droplet ( $V_{D} \approx$ $19 \mathrm{nl}$ ) prior to contact with the advancing sub-phase rivulet. (e) Droplet $\approx 0.1 \mathrm{~s}$ after contact with the sub-phase, in the process of getting mobilized. (f,g) Droplet in an early $(t=1 \mathrm{~s})$ and later stage of the propulsion ( $t=77 \mathrm{~s}$ ). The initially nearly half circular shape quickly relaxes towards a circular one. 
in contact with the surfactant droplet $(t=0)$, the latter is mobilized and slides onto the rivulet, as shown in Fig. 1(c,e). Subsequently, the surfactant droplet self-propels along the rivulet, whereby strong filmthinning behind the advancing droplet is evident. $\dagger$ Optical micrographs of droplet mobilization and self-propulsion along a chemically confined sub-phase film $\left(h_{0}=295 \mu \mathrm{m}\right)$ are shown in Fig. 1(d,e) and (f, g), respectively. The experiment was monitored using an Olympus BX-51 upright microscope, with the illuminating light passbandlimited around a center wavelength of $\lambda=650 \mathrm{~nm}$ with a bandpass of $\Delta \lambda \approx 10 \mathrm{~nm}$.

Fig. 2(d) shows the position $x_{D}$ of a droplet $\left(V_{D} \approx 23 \mathrm{nl}\right)$ as a function of time $t$ for propulsion on a sub-phase film of thickness $h_{0}$ $=325 \mu \mathrm{m}$ (black circles). To very good approximation the dynamics are described by a power-law of the form $x_{D}=t^{0.55}$.

As illustrated in Fig. 2(d), the propulsion speed can be adjusted by modulating the sub-phase viscosity. Experimental data is shown for an experiment at $55^{\circ} \mathrm{C}$ (green diamonds, $V_{D} \approx 9 \mathrm{nl}$ ) and at $25^{\circ} \mathrm{C}$ with $10 w t \%$ of DI-water added to the sub-phase (blue triangles, $V_{D}$ $\approx 13 \mathrm{nl}$ ), resulting in viscosities of $105 \mathrm{mPa}$-s and $152 \mathrm{mPa}-\mathrm{s}$ respectively (original sub-phase viscosity $\mu_{\text {sub }}\left(25^{\circ} \mathrm{C}\right)=870 \mathrm{mPa}$-s). In both cases the observed propulsion speed is strongly increased, while $x_{D}(t)$ remains well approximated by a power-law of the form $x_{D}=t^{0.55}$.

Self-propelling droplets can be used to transport solid cargo particles. As a model cargo we used poly-methyl-methacrylate (PMMA) beads, (Altuglass, density $=1.19 \mathrm{~kg} \mathrm{~m}^{-3}$ ). In Fig. 2(a)
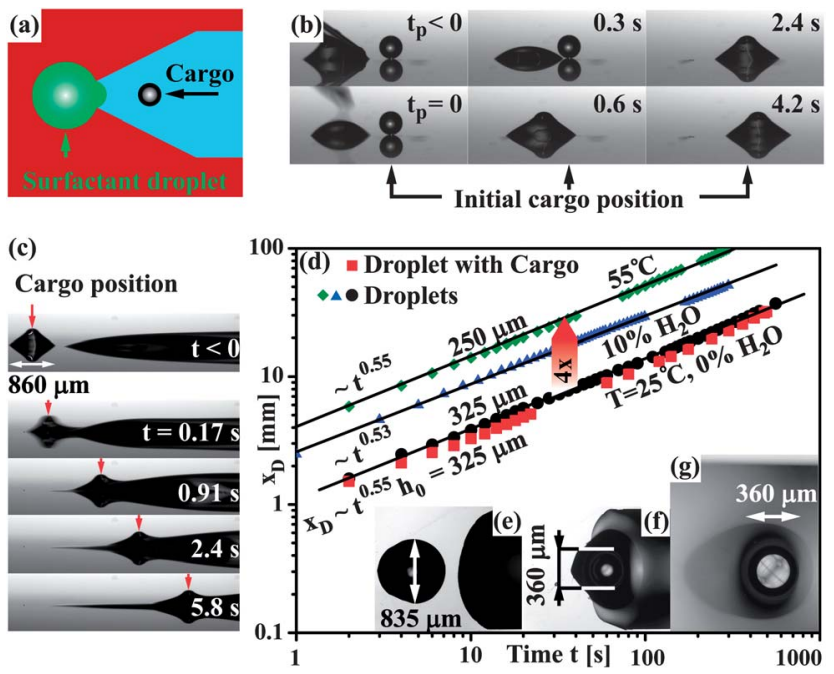

Fig. 2 (a) Sketch of the surface pattern used for cargo loading, prior to sub-phase deposition. A droplet deposited on the tip of the hydrophilic wedge propels forward towards the cargo due to the increasing hydrophilic surface area covered by it. (b) Experimental images of the cargo pick-up, taken with a telecentric lens in a side-view configuration. The initial cargo position is indicated by the black arrows on the bottom. (c) Mobilization and propulsion of a particle transporting droplet. The cargo position in the micrograph sequence is indicated by the red arrows. (d) Droplet position as a function of time for a droplet and a particletransporting droplet indicated by the black circles and red squares, respectively. Also shown, data for drop propulsion on sub-phase liquid with viscosities reduced by increased temperature (green diamonds) and addition of $10 w t \%$ DI water (blue triangles). (e-g) top-view images of a particle-transporting droplet, (e) prior to mobilization, (f) during mobilization, $(\mathrm{g})$ propelling with the particle. a chemical surface pattern is sketched that facilitates controlled pickup of a cargo particle by the droplets. Prior to sub-phase deposition, the particle is deposited inside a hydrophilic wedge, a surfactant droplet is deposited on the tip of the hydrophilic wedge $\left(t_{p}=0\right)$, moves forward and, provided its volume $V_{D}$ is sufficient, reaches the cargo particle and engulfs it. This short distance propulsion is based on the increase in hydrophilic surface area covered by the droplet as it moves forward in the hydrophilic wedge. ${ }^{21}$

Experimental images of a typical pickup process are shown in Fig. 2 (b) with the initial cargo position indicated by the black arrows on the bottom. After the surfactant droplet detached from the dippen $\left(t_{p}=0 \mathrm{~s}\right)$, it moved into the hydrophilic wedge, towards the cargo. When the droplet reached the cargo particle, it was initially drawn towards the droplet until it was completely engulfed $\left(t_{p}=0.6 \mathrm{~s}\right)$, after which it moved with the droplet along the hydrophilic wedge.

Following the pickup of the cargo particle, sub-phase is deposited and the mobilization of the droplet on the liquid sublayer occurs in the same fashion as for droplets without cargo. Experimental images of the mobilization and propulsion of a particle transporting droplets are shown in Fig. 2(c,e-g), for an experiment in side-view configuration and taken with an up-right microscope, respectively.

In Fig. 2(d) the position of a particle-conveying droplet is shown as a function of time by the red squares. It is evident that the droplet dynamics are basically equivalent with the ones for a droplet propelling without a cargo particle (black circles). We conducted experiments with as-received, hydrophobic beads as well as UV/ ozone-treated (10 $\mathrm{min})$, hydrophilic beads and found no difference in the transport behavior.

At binary junctions in the fluidic pathways, droplets can either be split or directed in one of the continuing branches. Experimental images of a splitting droplet $\left(V_{D} \approx 11 \mathrm{nl}\right)$ are shown in Fig. 3(a-c) $\left(h_{0}\right.$ $=250 \mu \mathrm{m})$. When the droplet reached the junction $\left(t_{j}=0\right)$ it extended orthogonally to its original propulsion direction. After thinning in its center region the droplet split up and both daughter droplets propelled independently along their respective fluidic branches. $\dagger$

By increasing the temperature of one of the junction branches, the droplets can be directed into the opposite branch, without breakup occuring. We used two different implementations to demonstrate this thermal steering, both for droplets with and without cargo. $\uparrow$ The first is depicted in Fig. 3(d). A small PDMS flow cell is attached to the bottom of the patterned glass substrate directly underneath one of the branches. Fig. 3(e-h) show experimental images of a droplet $\left(V_{D} \approx\right.$ $24 \mathrm{nl})$ steered at a junction using this implementation $\left(h_{0}=285 \mu \mathrm{m}\right)$. Shortly before $(\approx 2 \mathrm{~s})$ the droplets reached the junction, water with a temperature of about $10^{\circ} \mathrm{C}$ above ambient temperature $\left(25^{\circ} \mathrm{C}\right)$ was pumped through the flow cell at a flow rate of about $0.5 \mathrm{ml} \mathrm{s}^{-1}$. Due to the thin substrate thickness $(150 \mu \mathrm{m})$, the sub-phase film on top of the heated area quickly reaches the same temperature as the heating liquid. The droplets retracted from the heated branch and propelled along the unheated branch.

In the second configuration, heating was performed using a focused infrared laser beam $(\lambda=1470 \mathrm{~nm})$. The beam diameter at its focal point was $50 \mu \mathrm{m}$ and the output power of the laser was measured to be $1 \mathrm{~W}$. To ensure complete absorption of the laser beam, the patterned glass substrate was placed onto a Schott $K G-3$ infrared-absorbing glass slide. The entire setup was placed onto an inverted microscope to monitor the droplets. When they reached the junction $\left(t_{j}=0\right)$, the laser was triggered for $1.5 \mathrm{~s}$ to illuminate a spot 


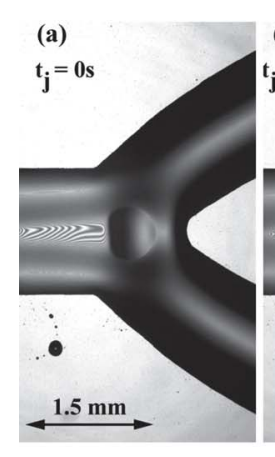

(b)
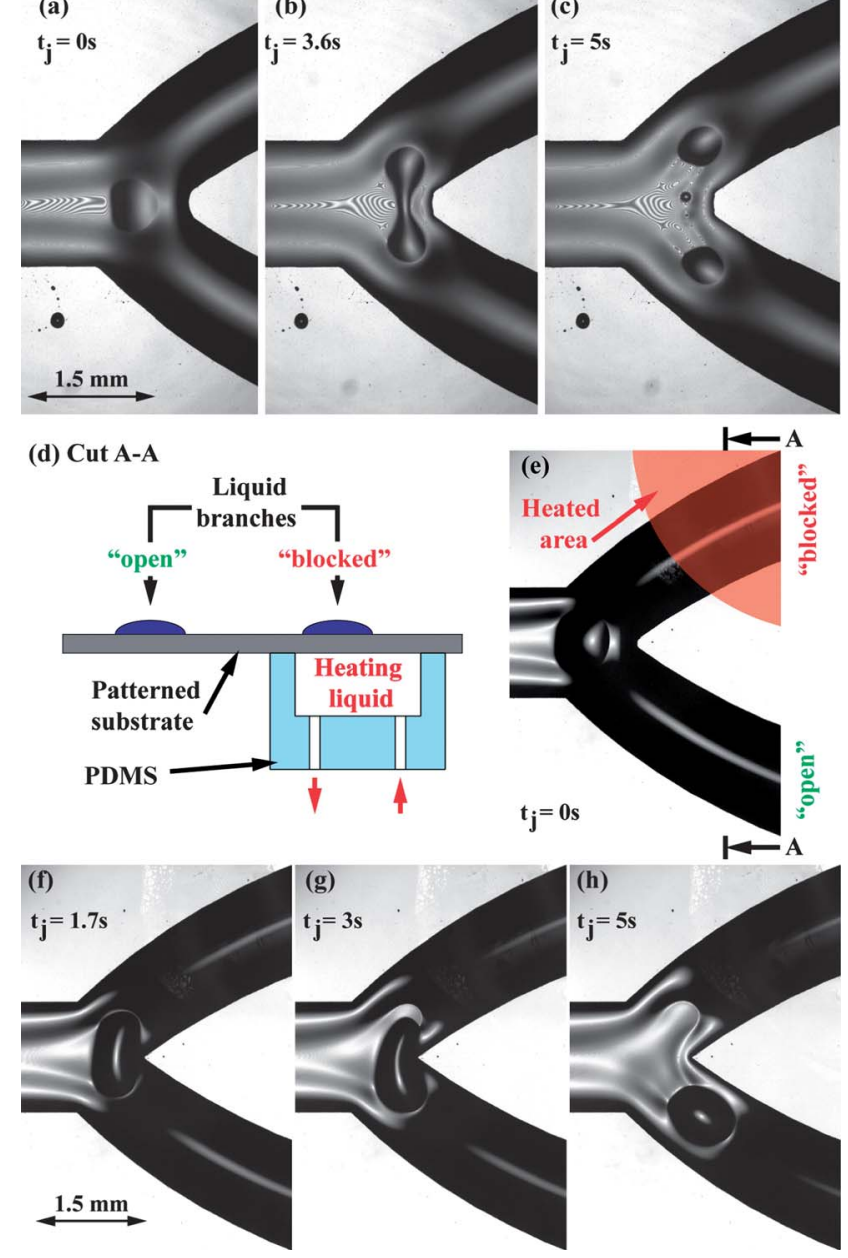

Fig. 3 (a-c) Interference microscopy images of a droplet splitting at a fluidic junction. After reaching the junction, (a), the droplet was stretched orthogonally to the rivulet, thinned in its center, (b), and split into two independently propelling droplets, (c). (d) Experimental configuration for heat induced droplet steering at fluidic junctions using a PDMS flow cell. (e-h) Microscopy images of a droplet steered at a fluidic junction. (e) Short before the droplet reached the junction at $t_{j}=$ 0 , heating liquid was pumped through the flow cell. The droplet was stretched orthogonally to its propulsion direction, (f), detached from the sub-phase liquid in the heated branch, (g), and moved into the unheated branch, (h).

approximately $1 \mathrm{~mm}$ ahead of the droplets in one of the branches. As before, the droplets reliably propelled along the unheated branch. $\dagger$

The mechanism underlying this thermal steering technique is a reduction of the interfacial and surface tension as well as a thermocapillary Marangoni stress opposing the surfactant-induced one in the heated branch. The resulting inequality of the capillary and contact line forces as well as Marangoni-stresses in the junction branches facilitates the described routing of droplets.

In summary, we presented droplets exhibiting self-sustained motion on liquid substrates, that can transport a solid particle and, at fluidic junctions, can be split or steered by thermal actuation. The independence from external power sources, integrated electrodes or heating elements for drop propulsion, makes the system specifically interesting for applications in inexpensive, single-use-type devices.

\section{Acknowledgements}

The authors thank Steffen Berg and Axel Makurat from Shell International Exploration and Production (Rijswijk, The Netherlands) for the inspiring collaboration and gratefully acknowledge the partial supported by the Dutch Technology Foundation STW, applied science division of NWO and the Technology Program of the Ministry of Economic Affairs.

\section{References}

1 S. Chao and D. R. Meldrum, Lab Chip, 2009, 9, 867-869.

2 K. Ichimura, S. Oh and M. Nakagawa, Science, 2000, 288, 1624-1626.

3 T. B. Jones, M. Gunji, M. Washizu and M. J. Feldman, J. Appl. Phys., 2001, 89, 1441-1448.

4 A. A. Darhuber, J. P. Valentino, J. M. Davis, S. M. Troian and S. Wagner, Appl. Phys. Lett., 2003, 82, 657-659.

5 V. Pratap, N. Moumen and R. S. Subramanian, Langmuir, 2008, 24, 5185-5193.

6 A. A. Darhuber, J. P. Valentino and S. M. Troian, Lab Chip, 2010, 10, 1061-1071.

7 S. Daniel, M. K. Chaudhury and P.-G. de Gennes, Langmuir, 2005, 21, 4240-4248.

8 J. Lee and C. Kim, J. Microelectromech. Syst., 2000, 9, 171-180.

9 M. G. Pollack, A. D. Shenderov and R. B. Fair, Lab Chip, 2002, 2, 96-101.

10 F. Mugele and J. Baret, J. Phys.: Condens. Matter, 2005, 17, R705R774.

11 M. Abdelgawad, S. L. S. Freire, H. Yang and A. R. Wheeler, Lab Chip, 2008, 8, 672-677.

12 M. Abdelgawad, M. W. L. Watson and A. R. Wheeler, Lab Chip, 2009, 9, 1046-1051.

13 G. M. Walker and D. J. Beebe, Lab Chip, 2002, 2, 131-134.

14 E. Berthier and D. J. Beebe, Lab Chip, 2007, 7, 1475-1478.

15 N. S. Lynn and D. S. Dandy, Lab Chip, 2009, 9, 3422-3429.

16 P. J. Resto, B. J. Mogen, E. Berthier and J. C. Williams, Lab Chip, 2010, 10, 23-26.

17 D. K. N. Sinz and A. A. Darhuber, unpublished work.

18 Y. Chen, Y. Nagamine and K. Yoshikawa, Phys. Rev. E, 2009, 80, 16303.

19 Y. Sumino, N. Magome, T. Hamada and K. Yoshikawa, Phys. Rev. Lett., 2005, 94, 068301.

20 D. K. N. Sinz, M. Hanyak, J. C. H. Zeegers and A. A. Darhuber, Phys. Chem. Chem. Phys., 2011, 13, 9768-9777.

21 J. Zhang and Y. Han, Langmuir, 2007, 23, 6136-6141. 